\title{
THE VALUE OF DENTAL EXAMINATION FOR EARLY DIAGNOSIS OF THE MUSCULOSKELETAL SYSTEM DISEASES
}

DOI: 10.36740/WLek202009223

\author{
Marina A. Shundryk, Iryna Y. Marchenko, Iryna M. Tkachenko, Viktor V. Boiko, Valeriy Y. Marchenko, Olga V. Sheshukova \\ UKRAINIAN MEDICAL STOMATOLOGICAL ACADEMY, POLTAVA, UKRAINE
}

\begin{abstract}
The aim: The purpose of the study was to determine the correspondence between the location of the tongue median line and the degree of distortion of the vertebral column at different levels in children with scoliosis.

Materials and methods: Totally 56 children (30 girls, 26 boys) aged 11-14 years were examined, with a duration of musculoskeletal disorders 1-3 years. For each participant an oral cavity examination was performed, the position of the middle line of the tongue was determined. X-ray images of vertebral column of the patients from investigated groups were analyzed.

Results: In the group with 1year duration of the disease $25.02 \%$ patients had a violation of the medial line of the tongue, in the group with 2 years of duration of the disease $65,52 \%$ participants had the deviation of the medial line of the tongue, in the group with 3 years of duration of the disease $86.66 \%$ of patients had the deviation of the medial line of the tongue.

Conclusions: This research allows us to recommend paying attention not only to the size, color, state of the papillae of the tongue, but also to the position of the middle line, which distortion may significate the deviation of the vertebral column in different portions.
\end{abstract}

KEY WORDS: posture, scoliosis, central line of the tongue deviation

Wiad Lek. 2020;73(9 p. II):2017-2019

\section{INTRODUCTION}

Until recent years pathologies of organs of the oral cavity and the mucouse membrane were considered as local pathological processes associated only with the bad hygienic condition of the oral cavity and the negative influence of pathogenic factors. However, modern researches and experimental models of the diseases allow us to establish that the oral cavity has a close anatomical and physiological relationship with various systems of the organism $[1,2,3]$.

Even ancient physicians used a tongue to decipher diagnostic symptoms of almost any human disease from its surface. Indeed, it can be stated that the violation of various organs usually manifested with changes in the surface of the tongue even before their pathological symptoms appear. Even with the disappearance of symptoms the tongue may indicate that the etiology of the disease remains unresolved and the full recovery did not happen.

Increasing sensitivity and discoloration of certain parts of the tongue reflects the disturbance of those organs associated with corresponding areas on its surface.

The localization of the plaque which covers the tongue indicates the accumulation of toxins in the stomach and small intestine (if the plaque is localized in the middle part of the tongue), in the large intestine (if the plaque is localized in the distal third of the tongue).

The surface of the tongue may reflect disorders in digestion, cardiac activity, nervous and endocrine systems.
In the literature there is data that the tongue can help in the diagnosis of many diseases, because its general appearance is in big relation with its anatomical features. Receptors of its mucous membrane are closely related with the central nervous, cardiovascular, endocrine and locomotor systems. $[3,5]$.

\section{THE AIM}

The purpose of the study was to determine the correspondence between the location of the tongue median line and the degree of distortion of the vertebral column at different levels in children with scoliosis.

\section{MATERIALS AND METHODS}

In order to achieve this goal, we performed our research on the basis of the Poltava regional sanatorium for children with musculoskeletal disorders. Totally 106 children ( 68 girls, 38 boys) aged 11-14 years were examined, with duration of musculoskeletal disorders 1-3 years (Tab 1). The comparison of the location of the median line of the tongue (photos) with the position of the spine (X-ray) in different departments cervical, thoracic, and lumbar was also performed.

\section{RESULTS AND DISCUSSION}

Scientific researches suggest posture problems as a factor affecting the occurrence of occlusion anomalies as well 
Table I. Dispersion of patients regarding to their age and duration of the disease.

\begin{tabular}{cccccc}
\hline \multirow{2}{*}{ Age } & \multicolumn{2}{c}{ N of patients } & \multicolumn{3}{c}{$\begin{array}{c}\text { Duration of the disease } \\
\text { (years) }\end{array}$} \\
\cline { 2 - 6 } & $\mathbf{n = 1 0 6}$ & \% & $\mathbf{1}$ & $\mathbf{2}$ & $\mathbf{3}$ \\
\hline 11 & 21 & 19.1 & 8 & 13 & 0 \\
\hline 12 & 23 & 20.9 & 7 & 13 & 3 \\
\hline 13 & 15 & 17.3 & 3 & 7 & 5 \\
\hline 14 & 47 & 42.7 & 11 & 19 & 17 \\
\hline
\end{tabular}
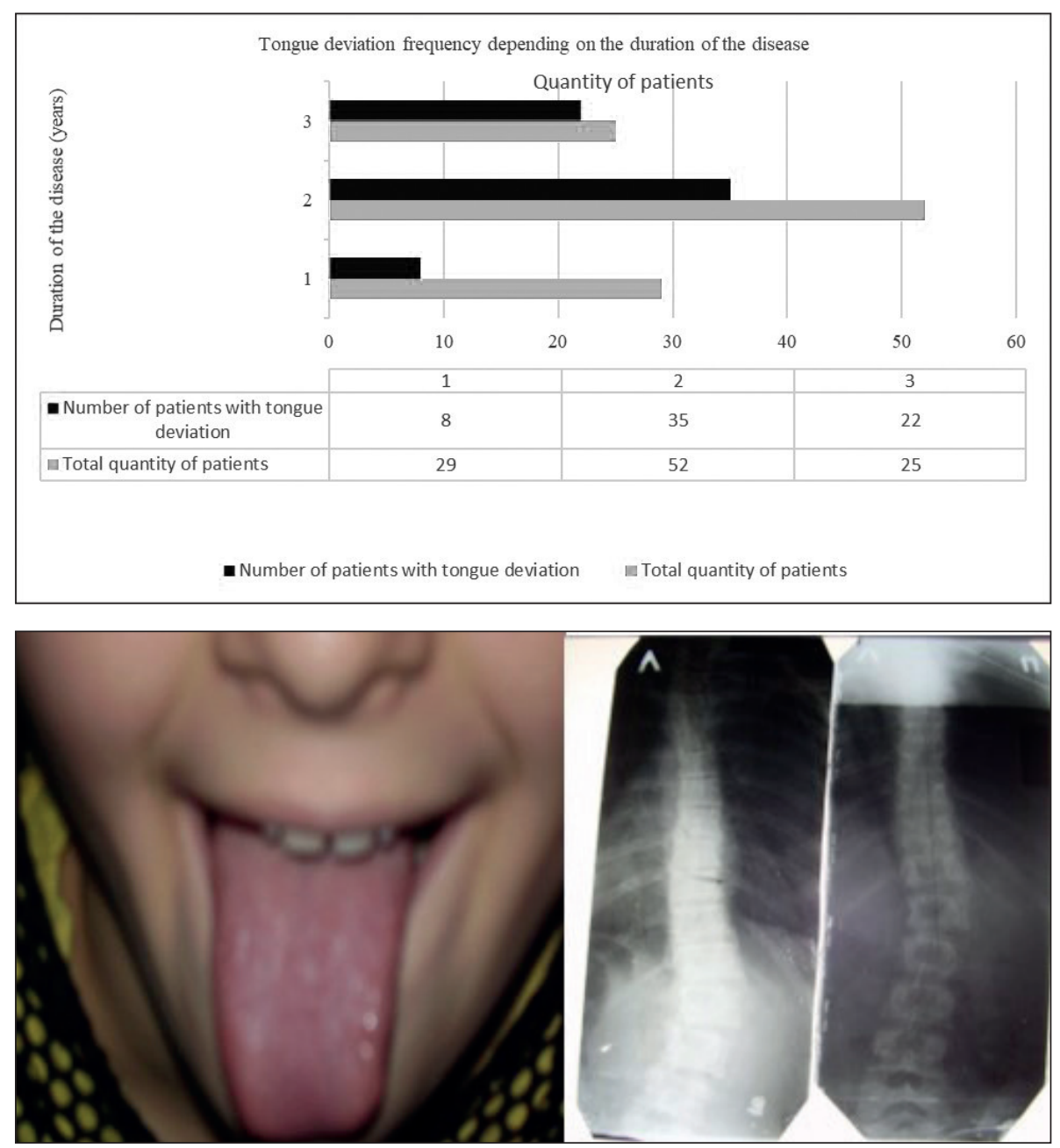

Fig. 1. Dispersion of the patients with the central line of the tongue deviation as their complications. In the case pathological occlusion (usually distal occlusion) an increased load on the constantly tensed occipital, ladder, thoracic-clavicular-osseous muscles) due to displacement of the center of gravity of the head augmentation. [4,5]. Taking into consideration the high mobility of the cervical portion of the vertebral column some preconditions for disfunction of all systems and organs appear. Especially for those located in the maxillo-facial area and exercising on the facial skull, cranial and spinal nerves, autonomic ganglia, vascular bundles, different muscles of the mentioned area, including mylohyoid and hyoglossus muscles, which cooperate with proper longitudinal and vertical muscles of the tongue.
The line which goes in the middle of it, accurately reflects the state of the human backbone. The curvature of the line on the tip of the tongue signs about the curvature of the vertebral column in the cervical portion, the one in the middle signs about problems in the thoracic part, at the root deviation corresponds to the curvature of the vertebrae in the lumbar section.

For the human spine three moderately pronounced physiological bends are natural. Cervical spine has a curve, convex forward, that begins at the axis at the apex of the odontoid process and ends at the middle of the second thoracic vertebra (lordosis). The thoracic curve, concave forward, begins at the middle of the second and ends at 
the middle of the twelfth thoracic vertebra (kyphosis). The lumbar curve begins at the middle of the last thoracic vertebra and ends at the sacrovertebral angle (lordosis).

Scoliosis is a pathological lateral curvature of the vertebral column with the obligatory rotation of the vertebral bodies. The characteristic feature of which is a progression of the disease, associated with age and growth of the child.

Unfortunately, nowadays disorders of the backbone are very common among children and adolescents. Especially scoliosis, which is 5-6 times more likely to occur in girls than in boys and also affects the reproductive function which makes it is a socially significant disease $[6,7]$.

Whereas the spine deformation reflects can affect the median fissure of the tongue appearance, dentists as firstline doctors communicating with wide sections of the population during examinations in kindergartens, schools or in clinics can easily suspect the pathology and inform the patient or his/her parents about it, thereby to prevent further development of the disease.

According to the dated received during the research it can be stated that the largest number of patients were children with duration of the disease for 2 years - 52 patients (47.3\%), for 1 year -29 patients (26.4\%), 3 years - 25 patients $(22.7 \%)$.

In the group with 1year duration of the disease $27,6 \%$ patients had a violation of the medial line of the tongue, In the group with 2 years of duration of the disease $67,3 \%$ participants had the deviation of the medial line of the tongue, In the group with 3 years of duration of the disease $88,0 \%$ of patients had the deviation of the medial line of the tongue (Fig. 1).

The curvature of the spine in the cervical region corresponded to the bend of the medial line of the tongue in the tip region, the bend of the spine in the thoracic region corresponded to the bend of the medial line of the tongue in the middle part, the bend of the spine in the lumbar region corresponded to the bend of the medial line of the tongue in the root area (Fig.2).

Statistical tests were significant and confirmed the dependence between the increase of tongue deviation frequency and the duration of spine disease. T-test: $\mathrm{p}=0.00 ; \mathrm{t}=21.28$; $\mathrm{df}=107$. ANOVA one-way test (deviation by duration comparison): $\mathrm{p}=0,00 ; \mathrm{F}=14,29 ; \mathrm{df}=2$ between groups, within each group $\mathrm{df}=105$.

\section{CONCLUSIONS}

Observation data give us the right to conclude that dentists can suspect the presence of spinal deformation without general examination and X-ray examination in patients with a disease duration period of at least 2-3 years during the preventive examination of children and adolescents.

This research allows us to recommend paying attention not only to the size, color, state of the papillae of the tongue, but also to the position of the middle line, which distortion may significate the deviation of the vertebral column in different portions.
This study suggests further elucidation of the mechanism of influence of the vertebral column condition and skeletal muscles influence on the muscles of the maxillofacial area, which are involved in the formation of occlusion and function of oral cavity organs.

\section{REFERENCES}

1. Vorobyov Ye.0., Dudchenko M.A., Zhdan V.M. Internal Diseases. Poltava: Divosvit; 2004. 175.

2. Danilevsky N.F., Leontyev V.K., Nesiy A.F., Razhny Zh.I. Diseases of the mucous membrane of the oral cavity. Moscow: 0JSC Stomatology. 2001: 131-138.

3. Fleece P.S., Dushin A.I. The relationship of distal occlusion, morphological and functional disorders of the spine. Ukrainian Dental Almanac. 2015; 1:75-77.

4. Ulitovskii S.B. Assessment of the tongue state. Dentistry maestro, 2006; 4:39-45.

5. Racine M.S., Skrypnikova T.P. Propaedeutics of internal diseases. Poltava; 2001.

6. Yumasheva G.S. Rheumatology and orthopedics. Moscow: Medicine; 1990. 215.

7. Shundryk M.A., Marchenko I.Y., Tkachenko I.M., Vodoriz Y.Y., Boyko V.V. The correspondence of the tongue central line deviation with the pathology of spinal curvature. The Medical and ecological problems. 2019; 23(1-2): 22-25.

\section{ORCID and contributionship:}

Marina A. Shundryk: 0000-0003-3186-5923 ${ }^{A, B}$

Iryna Y. Marchenko: 0000-0001- 7092-1786 ${ }^{C}$

Iryna M. Tkachenko: 0000-0001-8243-8644 ${ }^{D}$

Viktor V. Boiko: 0000-0002-1568-7576 ${ }^{E}$

Valeriy Y. Marchenko: 0000-0002-3048-7249 ${ }^{F}$

Olga V. Sheshukova: 0000-0002-4739-4890

\section{Conflict of interest:}

The Authors declare no conflict of interest.

\section{CORRESPONDING AUTHOR Marina M. Shundrik \\ Ukrainian Medical Stomatological Academy \\ 17 Zalizna St., 36001 Poltava, Ukraine \\ tel: +380508633626 \\ e-mail:shundrikliliya@gmail.com}

Received: 24.03 .2020

Accepted: 29.07 .2020

\footnotetext{
A - Work concept and design, B - Data collection and analysis, C - Responsibility for statistical analysis, D -Writing the article, $\mathbf{E}$ - Critical review, $\mathbf{F}$ - Final approval of the article
} 